\title{
MOVIMENTO AMBIENTALISTA E AS NOVAS MÍDIAS: ATIVISMO AMBINTAL NA INTERNET PARA A PROTEÇÃO JURÍDICA DO MEIO AMBIENTE
}

\author{
Márcio de Souza Bernardes ${ }^{1}$
}

\begin{abstract}
RESUMO
As novas mídias globais, caracterizadas pela interatividade, facilidade de acesso a crescente parcela da população mundial e pela velocidade da informação, modificaram o cenário político e jurídico contemporâneos, impulsionando o desenvolvimento de movimentos sociais que surgem com vocação global. Por esse motivo, essas mídias apresentam-se como instrumento privilegiado do movimento ambientalista que emerge dos anos de 1960-80, descentralizado, multiforme e orientado para a formação de redes no sentido de proteção do meio ambiente. Neste sentido o presente texto busca, primeiramente, a identificação das chamadas novas mídias bem como a sua relação com movimentos sociais contemporâneos. Posteriormente, busca-se uma análise dos principais objetivos e das formas de atuação do movimento ambientalista no que se refere às questões políticas e jurídicas, para, por fim, verificar a forma como as novas mídias possibilitam o chamado ativismo ambiental, através de ações que ultrapassam a simples informação e conscientização, mas que ganham dimensões concretas, com mudanças nos próprios centros de tomadas de decisões.
\end{abstract}

\section{INTRODUÇÃO}

Desde o surgimento das mídias de comunicação em massa, tais como jornais impressos, livros, rádio e televisão, decorrentes dos avanços tecnológicos da modernidade, ficou clara a sua influência no jogo político, possibilitando o surgimento de uma opinião pública e de um conjunto de ações destinados ou a manipulá-las ou a reder-se a ela, (re) modelando a democracia liberal.

As novas mídias globais, caracterizadas pela interatividade, facilidade de acesso à uma parcela crescente da população mundial e pela velocidade da informação, modificaram o cenário político e jurídico contemporâneos, proporcionando o desenvolvimento de movimentos sociais que surgem com vocação global, especialmente no que se refere à sua face ativista, qual seja, àquela que ultrapassa a mera conscientização sobre problemas locais e globais de interesse político, e busca soluções concretas, determinando modificações das tomadas de decisões e modificação de leis, construindo ações diretas e a crítica sistema capitalista, como recentemente

\footnotetext{
${ }^{1}$ Mestre em Direitos Sociais e Políticas Públicas pela Universidade de Santa Cruz do Sul (UNISC), Especialista em Direito Processual Civil pela Universidade Luterana do Brasil (ULBRA). Graduado Direito pela Universidade Federal de Santa Maria. Professor do Curso de Direito do Centro Universitário Franciscano (UNIFRA). Advogado. E-mail: msbernardes@ hotmail.com
} 

III SEMINÁRID ECDLDGIA

POLÍTICA

E DIREITO NA AMÉRICA LATINA

Com a utilização do método de abordagem hipotético-dedutivo, busca-se a confirmação da hipótese de que as novas mídias ultrapassam as funções da mídia tradicional e, no que se refere ao movimento ambientalista, proporcionam novas práticas políticas, jurídicas e sociais frente às questões ambientais. Foram analisados, para tanto, além da bibliografia apropriada algumas iniciativas na própria internet, ainda que de forma ampla, para compreender o explicar o fenômeno.

\section{AS NOVAS MÍdias E A PARTICIPAÇÃo POLÍtica NA SOCIEDAdE GLOBALIZADA}

A sociedade contemporânea passa por profundas e velozes modificações que atingem a forma pela qual se estabelecem as relações de poder e a democracia. Grande parte dessas modificações - senão a sua totalidade - está vinculada a emergências das novas tecnologias, especialmente aquelas ligadas à informação e comunicação (TICs). Assim, pode-se verificar que o estabelecimento de uma chamada pós-modernidade ${ }^{2}$ passa pelo aprofundamento e complexidade das comunicações em escala global, permitindo, desse modo, fluxos de informações, mercadorias, transações financeiras, trocas de experiências, remodelação da dimensão espaço-tempo, etc., que determinaram o surgimento da chamada sociedade em rede ${ }^{3}$ ou sociedade da informação.

Nesta primeira etapa, a proposta do presente texto restringe-se ao delineamento da sociedade de informação surgida a partir do que chamamos novas mídias, bem como a forma como elas se relacionam como movimentos sociais de vocação global, especialmente no que se refere às possibilidades de atuação política.

O surgimento das chamadas novas mídias possibilitaram recentemente a criação e utilização do termo de sociedade de informação, mostrando-se como uma forma de sociedade que está diretamente relacionada ao surgimento e popularização da tecnologia da computação e da rede de computadores, a world wide web, e que possibilita uma

\footnotetext{
${ }^{2} \mathrm{O}$ conceito de pós-modernidade é bastante complexo e engloba uma série de fatores sociais, culturais, econômicos, políticos e jurídicos, que não cabe, neste momento, aprofundar. Muitos autores trabalham o tema em suas diversas vertentes. Podemos citar, dentre eles, Stuart Hall, Perry Anderson, Zygmunt Bauman, Ulrich Beck, Antony Giddens, Boaventura Souza Santos, dentre outros.

${ }^{3}$ Termo utilizado como título da obra de Manuel Castells A sociedade em rede: a era da informação economia, sociedade e cultura, através da qual o autor busca demonstrar a construção contemporânea de uma sociedade interligada em diversos aspectos, e mediada pelas tecnologias de informação.
} 


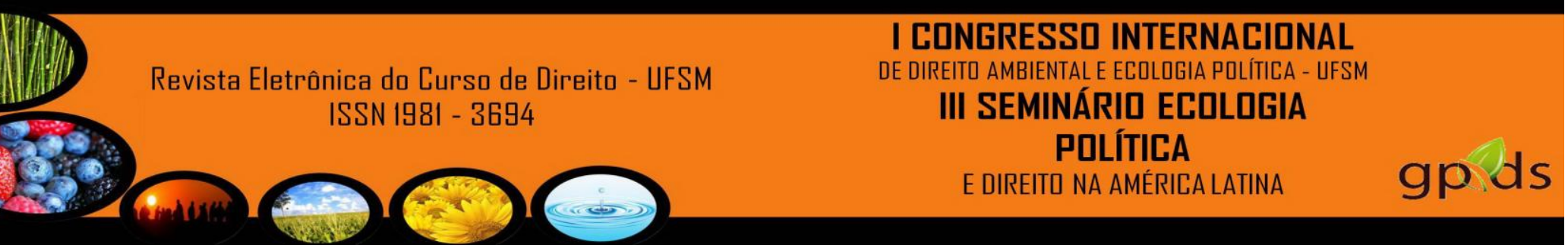

conectividade global, permitindo uma comunicação em tempo real jamais vista até então. Neste sentido Prudencio explica que

\begin{abstract}
Sociedade da informação é uma expressão recorrente nas análises recentes sobre a sociedade. Utilizada em diferentes contextos teóricos, designa geralmente um ambiente de relações sociais mediado por sistemas de informação cujo suporte tecnológico são as redes de computadores. A noção de conectividade que perpassa essas análises pressupõe uma sociedade global, na qual a informação está disponível numa rede eletrônica mundial de bibliotecas, arquivos e bancos de dados acessíveis, teoricamente, a qualquer pessoa em qualquer lugar a qualquer momento. (PRUDENCIO, 2006, p. 17)
\end{abstract}

Portanto, é no contexto da sociedade de informação ou em rede, que podemos problematizar as questões decorrentes das chamadas novas mídias (ligadas à tecnologia computacional), em contraponto às mídias tradicionais, cujos exemplos mais evidentes são os jornais impressos, rádio e $\mathrm{TV}^{4}$, especialmente na modificação de formas de participação democrática nesta sociedade caracterizada pela desterritorialização e indefinição das fronteiras do Estado-nação.

Ao contrário do que se pode vislumbrar do surgimento e evolução das chamadas mídias tradicionais, as relações sociais mediadas através das redes de computadores resultam numa modificação na forma de organização da sociedade que, de modo mais profundo e veloz, transforma suas instituições modernas. Com efeito, as formas pelas quais a informação e a comunicação são mediadas influenciam diretamente nas relações de poder na sociedade. Para Pierre Lévy (2003, p. 59) as infra-estruturas de comunicação e as tecnologias intelectuais sempre mantiveram estreitas relações com as formas de organização econômica e política.

$\mathrm{O}$ autor da obra Intenligência Coletiva sustenta sua afirmação argumentando que os primeiros Estados burocráticos, hierarquia piramidal e as formas iniciais de administração econômicas centralizadas estão ligadas ao nascimento da escrita que com a ampla difusão de livros e jornais a imprensa solidificou a opinião pública, sem a qual não teriam surgido as democracias modernas. Sustenta, além disso, prossegue afirmando que

\footnotetext{
${ }^{4}$ No que se refere à contraposição entre "novas mídias" e "mídias tradicionais", SANTOS (2010, p. 208) faz uma ressalva, demonstrando que os meios não são tradicionais porque são jornais impressos, televisões, rádios ou meios digitais, mas, sim, por seus valores e pelo jornalismo que praticam, independentemente do meio em que são difundidos.
} 
III SEMINÁRII ECOLDGIA

PDLÍTICA

E DIREITO NA AMÉRICA LATINA

a imprensa representa a primeira indústria de massa, e o desenvolvimento tecnocientífico por ela promovido foi um dos motores da Revolução Industrial. A mídia audiovisual do século XX (rádio, televisão, discos, filmes) participou do surgimento de uma sociedade do espetáculo, que transformou as regras do jogo tanto na cidade como no mercado (publicidade) (LÉVY, 2003, p. 60)

Contudo, muito embora as mídias tradicionais tenham se tornado um instrumento político fundamental entre os séculos XIX e XX, modificado o fazer político e, consequentemente, as relações do Estado com a sociedade e, ato-contínuo o próprio direito, as modificações que estão em curso em nosso tempo, especialmente a partir do surgimento da internet parecem escapar dos padrões construídos na sociedade moderna. Pierre Lévy (2003) expõe que nossas instituições ainda vigentes, como as formas de governo, foram criadas num momento em que as modificações técnicas, econômicas e sociais eram menos rápidas. As chamadas novas mídias, conformr Lévy (2003, p. 61) trouxeram uma informação torrencial e oceânica de modo que o hiato entre o caráter diluviano dos fluxos de mensagens e os modos tradicionais de decisão e orientação fazse cada vez mais evidente .

Esse oceano de informações presente na sociedade atual, e colocado à disposição através da internet, por outro lado, traz uma sensação de incerteza decorrente de uma modificação nas formas nos locais de tomadas de decisão. Há uma sensível modificação dos centros de poder decorrentes das interrelações estabelecidas nas redes que se formam, o que acaba gerando uma crise no próprio conceito de cidadania, a ponto de estar sendo constituída, nas palavras de Casltells (2007, p. 565) uma nova morfologia social de nossas sociedades e a difusão lógica de redes modifica de forma substancial a operação e os resultados dos processos produtivos e de experiência, poder e cultura. Para Prudencio

Essas mudanças na forma de fazer política, a incerteza gerada pela abundância de informação e a centralidade dos processos midiáticos na sociedade contemporânea desenham novos cenários para a ação coletiva. Movimentos sociais já não podem ser analisados sem uma articulação dessas problemáticas. Os protestos por justiça global são emblemáticos nesse sentido: eles atuam em rede, sem predominância deste ou aquele movimento particular, suas demandas são múltiplas, podendo convergir ou divergir, dependem da visibilidade para sua negociação e evidenciam a complexidade da vida social, na qual a fronteira entre público e privado não pode ser identificada facilmente. (PRUDENCIO, 2007, p. 36) 
movimentos sociais em sua trajetória e produtividade histórica, referente aos impactos em valores e instituições, poderíamos dizer que o movimento ambientalista do último quarto de século conquistou posição de destaque no cenário da aventura humana (CASTELLS, 2006, p. 141). Por sua natureza global, este movimento, ao contrário dos movimentos sociais até então existentes, surge com características transnacionais e de forma multissetorial ${ }^{5}$, vocacionado para desenvolver-se em uma sociedade em rede.

Espalhados na sociedade civil organizada e com base na opinião pública, o movimento ambientalista emerge justamente no período em que a ciência, de um lado, demonstra o possível esgotamento das bases de preservação do planeta, tanto físicas como biológicas, e que a tecnologia, de outro, dava impulso aos meios de comunicação em massa, de alcance global, modificando, no pós-guerra, as características da sociedade ocidental. Por isso que Manuel de Castells sustenta que

Existe uma relação direta entre os temas abordados pelo movimento ambientalistas e as principais dimensões da nova estrutura social, a sociedade em rede, que passou a se formar dos anos 70 em diante: ciência e tecnologia como os principais meios e fins da economia e da sociedade; a transformação do espaço; a transformação do tempo; e a dominação da identidade cultural por fluxos globais abstratos de riqueza, poder e informações construindo virtualidades reais pelas redes da mídia (CASTELS, 2006, p. 154).

Conforme McCormik (1992), é a partir da década de 60 que se inicia uma afirmação do movimento ambientalista como ativista político e social, de modo a pressionar as entidades oficiais internacionais no sentido de soluções, através do Estado e para além dele, para os problemas que se apresentavam.

As abordagens mais tradicionais enquadram o ambientalismo de três formas distintas: como grupo de pressão ou interesse; como movimento social, ou como movimento histórico. A primeira abordagem, surgida nos Estados Unidos, situa o ambientalismo como um grupo de pressão ou lobby dentro da própria institucionalidade,

\footnotetext{
${ }^{5} \mathrm{O}$ termo multissetorial é utilizado no sentido que lhe dão Eduardo Viola e Héctor Leis, no texto " $A$ evolução das políticas ambientais no brasil, 1971-1991: do bissetorialismo preservacionista para o multissetorialismo orientado para o desenvolvimento sustentável", traduzindo o movimento ambientalista como multissetorial por estar presente em diversos setores da sociedade, com sociedade civil organizada, (organizações não governamentais), estruturas governamentais, comunidade científica, grupos comunitários de base, empresariado, etc., que apresentam convergências quanto à emergência das questões ambientais e ecológicas, mas, ao mesmo tempo, destoam nas suas pautas de atuação para a resolução de tais problemas.
} 


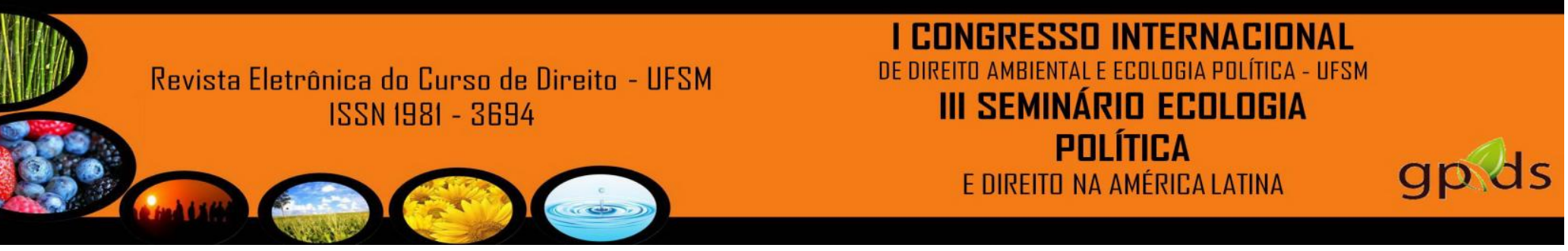

da democracia e cidadania, agora emergindo em um espaço desterritorializado, sem se afastar, contudo, das demandas locais e próprias de cada cultura.

\section{O MOVIMENTO AMBIENTALISTA E INTERNET: ATIVISMO AMBIENTAL NAS NOVAS MÍDIAS}

Por tudo o que até aqui se demonstrou, parece clara a vinculação entre o movimento ambientalista e a sua relação (congênita) com os meios de comunicação em massa, especialmente aqueles emergentes nos últimos vinte anos. É através da internet, e de suas múltiplas possibilidades como mídia interativa, através da qual os fluxos de informações (textos, fotos, vídeos) permitem um espaço de todos nós conectados e sujeitos ativos da comunicação, e não apenas passivos, que se percebe um movimento de pressão jamais visto em nossos tempos.

Os próprios governos dos Estados, numa perspectiva ampla, e não só relacionado à questão ambiental, já buscam alternativas para sua inserção neste espaço público virtual, como é o caso do Brasil, que apresentou, ainda no ano de 2000, um projeto de lei do chamado Programas de Governo Eletronico. Na página da internet, pode-se ler que

\footnotetext{
O desenvolvimento de programas de Governo Eletrônico tem como princípio a utilização das modernas tecnologias de informação e comunicação (TICs) para democratizar o acesso à informação, ampliar discussões e dinamizar a prestação de serviços públicos com foco na eficiência e efetividade das funções governamentais. (GOVERNO ELETRONICO. Conheça o gov.br. Acesso em: 16 de abr. de 2012).
}

Está-se diante de a construção de uma espécie de ágora virtual, nas palavras de Pierre Lévy (2003), através da qual se está gestando uma nova forma de atuação democrática, que o autor denomina de demodinâmica (do grego demos, povo e dynamis, força, potência), capaz de articular conhecimentos e formas de agir que demandam uma remodelação das tradicionais democracias. Segundo Lévy, a demodinâmica

surge do ciclo da escuta, da expressão, da avaliação, da organização, das conexões transversais a da visão emergente. Suscita a regulação em tempo real, o aprendizado coletivo contínuo, a valorização ótima das qualidades humanas e a exaltação das singularidades. A demodinâmica não se refere à um povo soberano, reificado, fetichizado, plantado em um território, 
III SEMINÁRID ECDLDGIA

identificado pelo solo ou pelo sangue, mas a um povo em potência, perpetuamente em vias de se conhecer e se fazer, em gestação, um povo futuro. (LÉVY, 2003, p. 82)

Exemplos claros dessa realidade são observados através da infinidade de sites, blogs, redes sociais como Orkut, facebook, twitter, etc., que em tempo real veiculam informações, pesquisas, dados estatísticos, bem como os fatos políticos que estão ocorrendo, permitindo a mobilização e a articulação de saberes e de pessoas, eclodindo, inclusive, com movimentos para além do virtual, com ocupações de ruas, e embates físicos entre os ativistas.

No que se refere especificamente ao movimento ambientalista, Manuel de Castells (2006), traz exemplo esclarecedor através do qual se verifica o ambientalismo na vanguarda das novas mídias como ferramentas de mobilização e organização pela internet.

Por exemplo, uma coalização de grupos ambientais nos Estados Unidos, Canadá e Chile, formada a partir dos friends of the Earth, Sierra Club, Greenpeace, Defenders of Wildlife, The Canadian Enrironment Law Associatoin e muitos outros, mobilizou-se contra a aprovação da Associação Norte-Americana de Livre Comercio (NAFTA) por causa da insuficiência de dispositivos legais de proteção ambiental no acordo. Eles usaram a internet para coordenar ações e trocar informações, construindo uma rede permanente que passou a traçar as linhas de batalha da ação ambiental transnacional nas Américas na década de 90. (CASTELLS, 2006, p. 162)

Verifica-se, assim, que neste contexto, nas palavras de Castelles (2006, p. 163) que o ambientalismo não pode ser considerado meramente um movimento de conscientização. Desde o início, procurou exercer influência na legislação e nas atitudes tomadas pelos governos. Em outras palavras, as ferramentas possibilitadas por este novo espaço comum, que não mais é, de forma simplista, controlado pelas novas mídias, mas é decorrência de seu próprio sistema, cria novas demandas e pressões, modificando, no que se refere à questão ambiental, a produção de leis e políticas públicas referentes à proteção ambiental.

Está-se diante, portanto, de um verdadeiro ativismo virtual no que se refere ao meio ambiente, que, no entanto, ultrapassa o espaço virtual e se estabelece no mundo físico através de modificações concretas das legislações.

Fenômenos recentes no Brasil, e que ganharam escala mundial através das redes de computadores, ainda em disputa e andamento, são a construção da usina hidrelétrica 
de Belo Monte, no rio Xingu, e a modificação da Lei 4.771/1965, o chamado código florestal. Pesquisas com os verbetes Belo Monte e novo código florestal, no site de busca Google, na internet revela a forma como a informação e as possibilidades de análises destas situações surgem neste espaço.

Para a pesquisa do termo "belo monte”, verifica-se que, em 0,15 segundos, temse o acesso à 1.010.000 (um milhão e dez mil) possibilidades de pesquisas, entre jornais virtuais, blogs, sites especializados, sites oficiais (governamentais), etc.. Não é diferente a pesquisa quanto ao termo "novo código florestal", que apresenta 4.090.000 (quatro milhões e noventa mil) ocorrências em menos de 0,14 segundos. O próprio Senado Federal disponibilizou, em seu sítio, um espaço próprio para informações e discussões acerca da alteração do Código Florestal.

Muitas destas ocorrências, tanto numa como noutra situação, mostram a situação das demandas públicas, os prós e contras das decisões, os riscos ambientais trazidos, bem como conclama a população às ações de pressão direta junto aos órgãos oficiais. Está-se diante, pois, de um novo ativismo, num novo espaço público, que remodelam as relações de poder e possibilitam, assim, uma opinião pública aberta à transformações contínuas e cada vez mais velozes, dentro da ágora virtual, onde a multiplicidade e a variedade ocupam lugares políticos dinâmicos.

\section{CONSIDERAÇÕES FINAIS}

Da pesquisa, ainda que panorâmica, dos exemplos analisados e que estão em andamento no Brasil, nos casos do Código Florestal e da usina hidrelétrica de Belo Monte, bem como das análises de situações como as demonstradas pelos autores trabalhados, não restam dúvidas que estamos em meio a uma profunda transformação social impulsionada pelas chamadas novas mídias.

Se antes, como o surgimento das mídias tradicionais, possibilitou-se o desenvolvimento da opinião pública e o surgimento das democracias - bem como, por vezes a sua manipulação e a formação de estados totalitários -, as novas mídias, mais especificamente a internet, possibilitam um espaço de trocas de informações, fotos, vídeos, artigos, pesquisas, etc., em volumes e em tempo nunca antes imaginados. Tais situações se mostram propicias para o ativismo ambiental, engendrado através do 


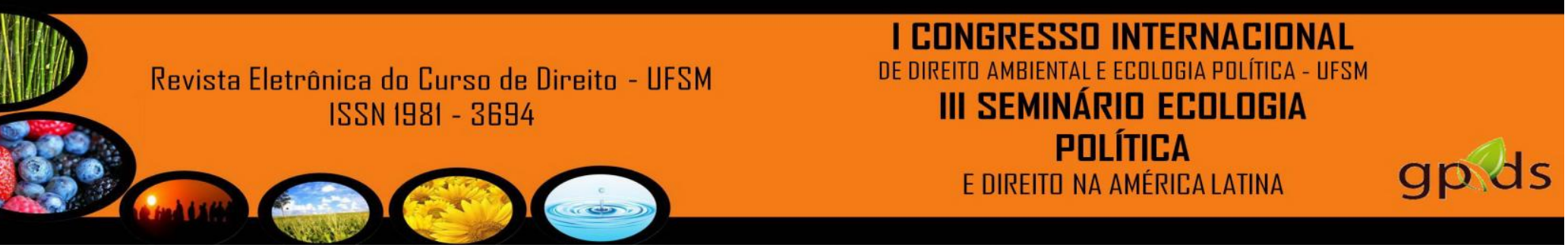

chamado movimento ambientalista, que nasce de forma conjunta com as mídias globais, a ponto de apresentar-se como o movimento que melhor demonstra as possibilidades políticas e sociais decorrentes do uso da internet.

Muito embora ainda se tenha um longo caminho a percorrer, especialmente dentro das ciências sociais e humanas, uma vez que se trata de um fenômeno bastante novo, pode-se arriscar a conclusão de que estas novas mídias, aliadas a estes novos movimentos sociais globais, especificamente o movimento ambientalista, caminham no sentido de reestruturar toda a sociedade, especialmente suas formas de organização política e jurídica, rumando para um futuro ainda incerto, mas certamente pleno de possibilidades e multiplicidades de decisão e ação.

\section{REFERÊNCIAS BIBLIOGRÁFICAS}

CASTELLS, Manuel. A sociedade em rede: a era da informação - economia, sociedade e cultura. vol. 1. 10 ed.Tradução de Roneide Venâncio Majer. São Paulo: Paz e Terra, 2007

O Poder da Identidade: a era da informação - economia, sociedade e cultura, Vol 2. Tradução de Klauss Brandini Gerhar. 5 ed. São Paulo: Paz e Terra, 2006.

GOVERNO ELETRÔNICO. Conheça o Gov.br. Disponível em: http://www.governoeletronico.gov .br/o-gov.br/. Acesso em 16 de abril. de 2012

LEIS, Héctor Ricardo. A modernidade insustentável: as críticas do ambientalismo à sociedade contemporânea. Florianópolis: Vozes, 1999.

LÉVY, Pierre. A inteligência coletiva: por uma antropologia do ciberespaço. $4^{\mathrm{a}}$ Ed. LOYOLA, São Paulo, 2003.

McCORMIK, John. Rumo ao paraíso: a história do movimento ambientalista. Rio de Janeiro: Relume-Dumará, 1992.

PRUDENCIO, Kelly Cristina de Souza. Mídia ativista: a comunicação dos movimentos por

justiça global na Internet. Florianópolis: UFSC, 2006. 207 p. Tese (Doutorado) Programa de

Pós-graduação em Sociologia Política, Centro de Filosofia e Ciências Humanas, Universidade

Federal de Santa Catarina, Florianópolis, 2006. 




SANTOS, Rafael Oliveira. A mídia como ator emergentes das relações internacionais: seu protagonismo no uso do soft Power frente aos desafios das mudanças climáticas. Florianópolis: UFSC, 2010. 419 p. Tese (Doutorado) - Programa de Pós-Graduação em Direito, Universidade Federal de Santa Catarina, Florianópolis, 2010.

VIOLA, Eduardo; LEIS, Hector Ricardo. A evolução das políticas ambientais no Brasil, 1971-1991: do bissetorialismo preservacionista para o multissetorialismo orientado para o desenvolvimento sustentável, in Daniel Joseph Hogan e Paulo Freire Vieira (Orgs.) Dilemas Socioambientais e Desenvolvimento Sustentável. Campinas, Ed. UNICAMP, 1995. 